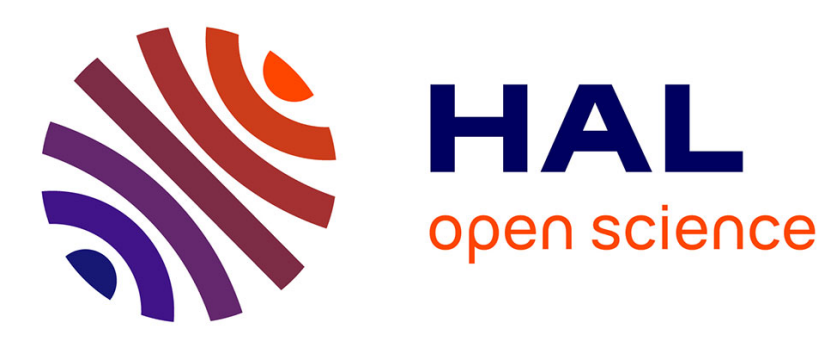

\title{
Semantic-Driven Architecture for Autonomic Management of Cyber-Physical Systems (CPS) for Industry 4.0
}

Ernesto Expósito

\section{To cite this version:}

Ernesto Expósito. Semantic-Driven Architecture for Autonomic Management of Cyber-Physical Systems (CPS) for Industry 4.0. MEDI 2019 International Workshops, DETECT, DSSGA, TRIDENT, Toulouse, France, October 28-31, 2019, Proceedings, Oct 2019, Toulouse, France. pp.5-17, 10.1007/978-3-030-32213-7_1. hal-02432944

\section{HAL Id: hal-02432944 https://hal-univ-pau.archives-ouvertes.fr/hal-02432944}

Submitted on 24 Jan 2020

HAL is a multi-disciplinary open access archive for the deposit and dissemination of scientific research documents, whether they are published or not. The documents may come from teaching and research institutions in France or abroad, or from public or private research centers.
L'archive ouverte pluridisciplinaire HAL, est destinée au dépôt et à la diffusion de documents scientifiques de niveau recherche, publiés ou non, émanant des établissements d'enseignement et de recherche français ou étrangers, des laboratoires publics ou privés. 


\title{
Semantic-driven architecture for autonomic management of Cyber-Physical Systems (CPS) for INDUSTRY 4.0
}

\author{
Ernesto Exposito [0000-0002-3543-2909] \\ Univ Pau \& Pays Adour, E2S UPPA, LIUPPA, EA3000, Anglet, 64600, France \\ ernesto.exposito@univ-pau.fr
}

\begin{abstract}
Today we are living a new industrial revolution, which has its origin in the vertiginous deployment of ICT technologies that have been pervasively deployed at all levels of the modern society. This new industrial revolution, known as Industry 4.0, evolves within the context of a totally connected CyberPhysic world in which organizations face immeasurable challenges related to the proper exploitation of ICT technologies to create and innovate in order to develop the intelligent products and services of tomorrow's society. This paper introduces a semantic-driven architecture intended to design, develop and manage Industry 4.0 systems by incrementally integrating monitoring, analysis, planning and management capabilities within autonomic processes able to coordinate and orchestrate Cyber-Physical Systems (CPS). This approach is also intended to cope with the integrability and interoperability challenges of the heterogeneous actors of the Internet of Everything (people, things, data and services) involved in the CPS of the Industry 4.0.
\end{abstract}

Keywords: Semantic-driven architecture, Cyber-Physical Systems, Industry 4.0, Autonomic Computing.

\section{Introduction}

The 18th century witness the advent of the first industrial revolution that was mainly characterized by the introduction of mechanical capabilities in the manufacturing processes based on power generated by steam engines. Mass production lines based on electrical energy are at the origin of the second industrial revolution towards the 20th century. These first two revolutions were mainly based on advances related to energy sources. In contrast, the third industrial revolution that began in the 1970s had its main origin in the arrival of the computer and the programming capabilities offered to automate manufacturing processes.

Today we are living a new industrial revolution named Industry 4.0, that is directly related to the accelerated advances enabled and promoted by information and communication technologies (ICT). A key element that allows us to understand this new revolution is the fact that we live in an increasingly connected world (i.e. connected humans, things, systems and data). In this context, all organizations, including absolutely all industrial or service sectors, are faced to tremendous challenges on how to exploit this full-connected paradigm. These challenges can be grouped into two main types: 
how to define adequate strategies to exploit the huge amounts of generated data and how to define and integrate the required action plans in order to provide smart products and services of the Industry 4.0 era.

To meet these challenges, organizations of this new digital revolution need to adopt and efficiently apply a rich and complex set of new technologies, including the Internet of Things, social networks, cloud computing, big data or artificial intelligence, among others. However, the transition from a traditional organization to a 4.0 era organization is a very complex process to achieve and requires an appropriate methodology and a concrete reference architecture allowing to respond to the challenges mentioned above.

A significant number of works have been interested in proposing solutions to meet the challenges of designing and developing solutions for the Industry 4.0. In particular, important initiatives coordinated by government agencies and private organizations from countries with the most developed economies (USA, Germany, China and Japan) have been established in order to propose reference architectures that will enable a smooth transition from traditional organizations to the 4th Industrial Revolution, as well as to foster a favorable environment for innovation and creativity for new companies and emerging markets.

However, these initiatives and their reference architectures have different foundations and orientations which, despite fulfilling their role as a guideline and roadmap, do not encourage interoperability and the reuse of common efforts. This paper is interested in identifying the key and common aspects of these different abstract reference architectures in order to propose a concrete reference architecture, based on a semanticdriven architecture (SDA) approach and able to respond to the main challenges of the cyber-physical systems of Industry 4.0: integration, interoperability and process management for the development and operations of intelligent products and services.

This paper is structured as follows: the next section describes the background and explicitly defines the challenges of organizations of the 4th industrial revolution. The third section introduces the reference architectures developed by major global initiatives. The fourth section presents our proposal for a semantic-driven architecture intended to design, develop and manage Industry 4.0 systems by incrementally integrating monitoring, analysis, planning and management capabilities within autonomic and cognitive processes able to coordinate and orchestrate Cyber-Physical Systems (CPS). Finally, the conclusions and perspectives of this work are presented.

\section{Background and challenges statement}

Industrial revolutions have been mainly induced by energy or technological discoveries that have had far reaching economic, political, social and human impacts. The first industrial revolution was recognized as such towards the middle of the 18th century and was characterized by a major transformation in production processes, from manual operations to mechanized operations thanks to the power generated by steam engines [1], [2], [3]. Towards the end of the 19th century, the second industrial revolution appeared, again driven by a new source of energy: the electricity. This revolution was characterized by the massification of production and also by a transformation in the role played 
by human beings, who instead of having global knowledge or skills, should specialize, thus optimizing processes thanks to the division of labor. The third revolution, which began in the 1970s, had a different origin: it is not due to the emergence of new sources of energy, but to technological advances related to the information and communication technologies (ICT) [4]. Indeed, the automation of several production processes was boosted by the computer and its programming capabilities.

Today we are living a new industrial revolution, which has its origin in the vertiginous and accelerated deployment of ICT technologies [5]. This new industrial revolution, called Industry 4.0, takes place within the context of a fully connected world and extends beyond industrial processes automation to include the design, development and operations of intelligent products and services of tomorrow's society. Huge challenges are ahead for existing and future societies of any scale, which must embrace these vast technological advances in order to innovate and develop future markets for products and services. These challenges can be grouped into two main types: how to define adequate strategies to exploit the huge amounts of data obtained from a fully connected world and how to define and integrate agile and context-aware action plans within the smart products and services required by the Industry 4.0.

In order to guide organizations in meeting these challenges, this article proposes to examine this phenomenon through three facets: contextualization of the connected world paradigm, strategies for processing the collected data to yield information and knowledge, and capacity to develop decision models and actions strategies for delivering intelligent products and services.

\subsection{Fully connected world paradigm}

For some years now, the boundaries between the physical world and the computing space have been narrowing drastically and we have been approaching at an accelerated pace towards a Fully Connected World (FCW).

Initially, it was the "things" that began to get connected giving birth to the concept of Internet of Things (IoT) and the enormous opportunities envisioned [6], [7], [8]. In the same vein, the idea of connecting machines and allowing communication between them gave rise to the concept of machine-to-machine (M2M) [9]. In order to foster interoperability, the concept of Web of Things (WoT) was proposed to encompass open protocols and facilitate access to the connected things [10].

The approach of interconnecting things or machines was opportunely extended by Cisco in 2013 to identify new markets and innovations opportunities leading to the fully connected world: The Internet of Everything (IoE) or the intelligent connection of people, things, data and process [11]. This vision has been naturally associated with other definitions such as the Internet of Data (IoD), Internet of Services (IoS) and Internet of People (IoP) [12], [13], [14]. 


\subsection{Data, information and knowledge challenge}

In the FCW paradigm, the amount of collectable data grows exponentially and the need for its processing, very often in real time, is essential to produce meaningful information and in particular to create new knowledge.

Existing solutions in the area of Business Intelligence (BI), Analytics or Artificial Intelligence (AI) have been successfully applied for years on the basis of data gathered from traditional information systems in order to support strategic decision making [15]. However, the quantity, heterogeneity and frequency of the potentially collectable data under the FCW paradigm of the Industry 4.0, reveal new challenges that will lead important innovations in the area of Big Data [16], [17].

\subsection{Acting upon a fully connected world challenge}

The second major challenge of the fourth industrial revolution is represented by the need to design intelligent systems capable of making the right decisions so that they can act on their environment, with or without human intervention, in order to adapt the offered products and services, while minimizing costs and maximizing customer satisfaction.

Several works have converged in proposing the Cyber-Physical Systems (CPS) as the adequate solution to offer this type of intelligent control through the dynamic and goal-oriented coordination of physical and computational entities [18], [19].

However, despite the fact that this solution seems to be the most adapted to respond to the needs of intelligent control of products and services stated for Industry 4.0, today there are still a significant number of unknowns in this regard: there is no clear definition of what a CPS should offer as an automated or semi-automated control service, there is no reference implementation architecture, the interaction interfaces with the coordinated entities have not been standardized, among others [20].

In addition, the complexity related to the coexistence of multiple CPSs able of cooperating or collaborating within the framework of Cyber Systems of Systems (CPSoS) on the basis of the exchange of resources and services and in order to achieve common and/or individual objectives has not been fully addressed

\section{$3 \quad$ Architectures of reference}

In order to lead traditional organizations in their transition to the 4th Industrial Revolution as well as to create an enabling environment for innovation and creativity for emerging businesses and markets, several initiatives have been initiated worldwide and several architectures of reference have been promoted.

\subsection{Industry 4.0 initiatives}

The most significant initiatives have been accompanied by government agencies and private organizations from countries in the most developed economies [21], [22]. 
One of the most significant initiatives is the one presented by the German industry under the name Industrie 4.0. This initiative is aimed at identifying and guiding the use of technologies able to revolutionize the manufacturing industry [23]. To achieve this and to establish a common understanding of this technological revolution, the Reference Architectural Model Industrie 4.0 (RAMI4.0) has been proposed. This is one of the reference architectures that has had the biggest impact worldwide and will be part of our study.

The second most important initiative is represented by the Industrial Internet Consortium (IIC), created by the most important US companies in the area of telecommunications and new technologies [24]. This initiative has proposed the Industrial Internet Reference Architecture (IIRA). This second reference architecture has been developed independently from the RAMI 4.0 architecture and consequently there are important differences between the dimensions of interest as well as the architectural features of both propositions. In our work we are interested in identifying and bringing together the main advantages provided by both reference architectures.

Among the large number of existing initiatives, we can also identify those launched on the Asian continent under the name Made in China 2025 [25] and the Japanese Industrial Value Chain Initiative (IVI) [26]. Both initiatives promote collaboration and common understanding of technologies capable of accelerating the modernization of the industries of the future.

Due to the impact obtained and the vast potentialities identified, this study will concentrate on the main reference architectures, namely RAMI 4.0 and IIRA.

\subsection{Industry 4.0 reference architectures}

As previously indicated, the RAMI 4.0 and IIRA architectures seek to promote a knowledge-sharing paradigm of Industry 4.0, in order to guide organizations in their transition and in particular to advise on the use of the ICT advances. The common point of the two initiatives lies in projecting organizations towards a more intelligent world. Both propose a systemic vision aimed at building complex, connected and intelligent systems. The main difference is that RAMI 4.0 extends this vision to encompass the entire value chain and product lifecycle, while IIRA retains a more concrete vision of the ICT world.

\section{Industrial Internet Reference Architecture (IIRA).}

The IIRA proposes a standards-based open architecture for the Industrial Internet of Things (IIoT). IIRA defines 4 viewpoints: Business (stakeholders and business vision), Usage (expected IIoT system usage), Functional (functional components of the IIoT system) and Implementation (technologies involved to implement the functional components). In particular, the functional view is decomposed into five functional domains: control domain (closed-loop control involving sensing, control and actuation), operations domain (management and maintenance), information domain (data collection and 
analysis), application domain (application use-case oriented functions), business domain (business goals-oriented functions). These functional domains are analyzed within two dimensions: the system characteristics to be guaranteed and the system-wide crosscutting functions.

Additionally, IIRA proposes two concerns related to the multilayered viewpoints architecture: the scope of applicability (diversity of industrial sectors) and system lifecycle process (IIoT system conception, design and implementation). The figure 1 summarizes the IIRA reference architecture.

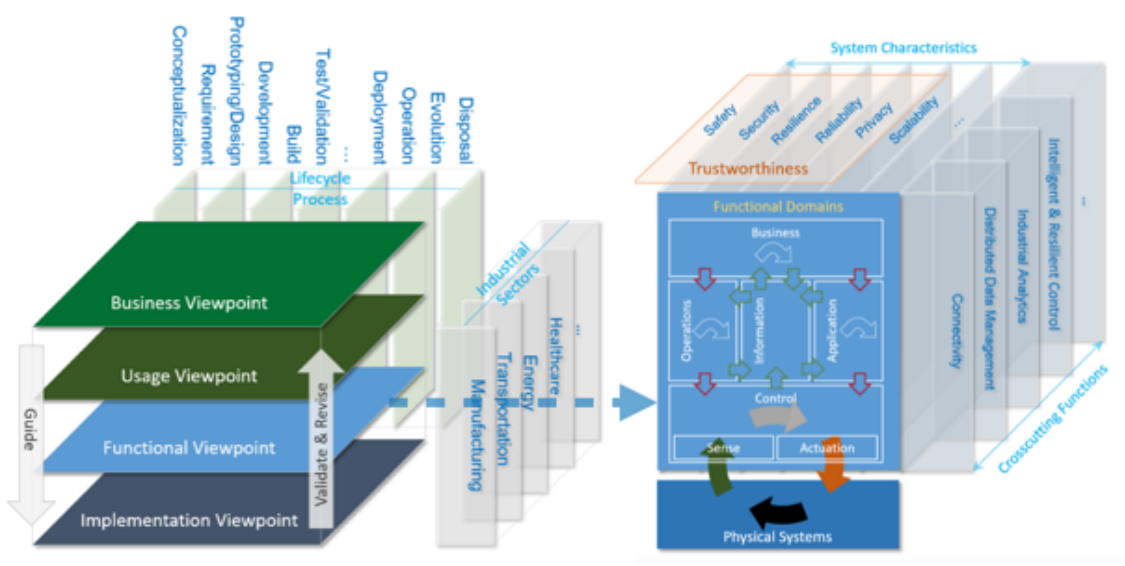

Fig. 1. Industrial Internet Reference Architecture (IIRA)

\section{Reference Architectural Model Industrie 4.0 (RAMI4.0)}

The RAMI reference architecture is based on tree axis including: the hierarchy levels dimension (from the product to the enterprise and connected world), the life cycle and value stream dimension (product conception and production) and the layered dimension (properties and system structures). The figure 2 presents the RAMI 4.0 reference architecture.

The first axis represents the hierarchy levels dimension that clearly characterizes the Industry 4.0 revolution. The highest level represents the connected world, the lower level the smart products and the intermediate levels the smart factory involving field and control devices as well as the stations, work centers and the whole factory.

The second axis targets the main goal of the industry: the whole product lifecycle. It distinguishes two phases. The first is the type phase, where the plans for the development to the maintenance of the product is conceived from the original idea. The second is the instance phase, where each product (the instance) is really produced and maintained.

Finally, the third axis proposes a 6 layered dimension including: asset (representing the physical things of the real world), integration (enabling cyber-physical transition), 
communication (enabling access to the information), information (collection and processing of relevant data), functional (asset's functionalities), business (organization goals and business processes).

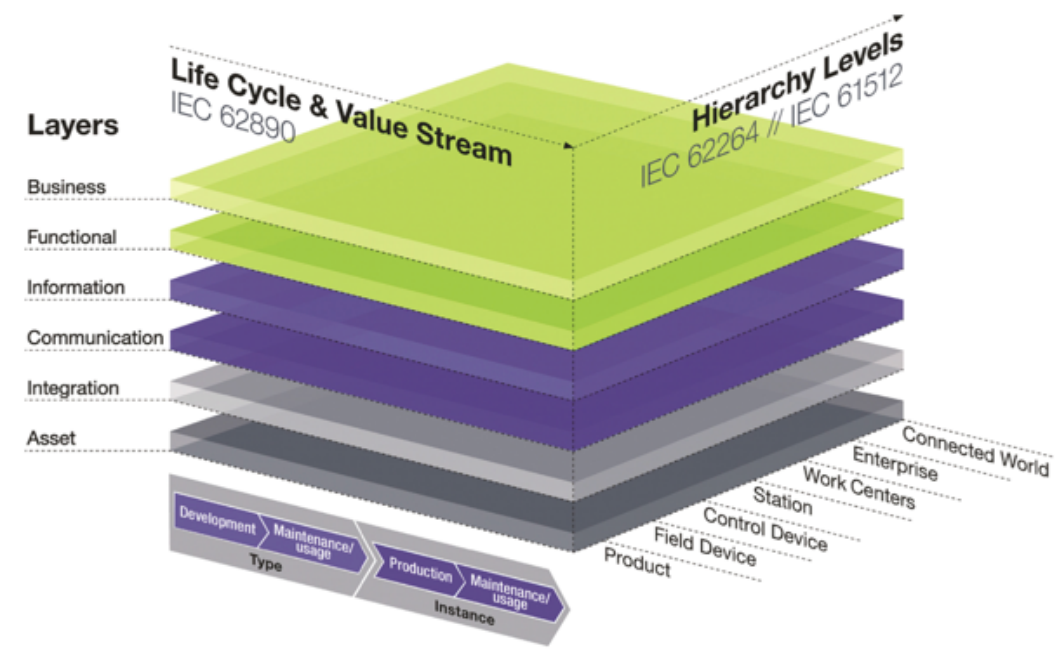

Fig. 2. Reference Architectural Model Industrie 4.0 (RAMI4.0)

\section{Semantic-driven architecture for autonomic CPS}

Based on the challenges identified for the solution carriers of the 4th industry revolution as well as on the main reference architectures promoted by international initiatives, this section presents a series of proposals in order to guide the design and development of solutions for Industry 4.0. Although the community mainly privileges the manufacturing processes for the elaboration of intelligent products, our proposal also extends to the area of intelligent services.

In both reference architectures previously described a systemic vision aimed at building complex, connected and intelligent systems is proposed. Although the IIRA architecture privileges the term Industrial Internet of Things (IIoT), it could be generalized that both reference architectures are oriented towards the development of a type of intelligent system that can be represented by the Cyber Physical Systems. Indeed, Industry 4.0 systems are characterized by being composed of physical and computational entities that interact intelligently in order to achieve specific objectives, such as for example the intelligent products and services targeted by the Industry 4.0.

In order to ensure that the objective of common understanding and integration of new technologies in the framework of the Industry 4.0 can be guaranteed in a tangible way, it is necessary to extract the key elements of these reference architectures, in particular to guide the design and development of Cyber Physical Systems.

This proposal includes the identification of a suitable methodology as well as the proposal of a generic and concrete architectural framework, based on semantic models and resulting from the reference architectures previously presented. 


\subsection{System engineering methodology}

Conscious of the need to guide the bearers of new ideas as well as those in charge of carrying out the digital transformation of traditional production and service companies, our proposal is oriented towards the identification and specialization of a methodology suitable for the design of complex systems and capable of integrating the challenges of Industry 4.0.

In the area of software engineering and systems engineering, several methodologies and modeling frameworks have been proposed for the development of complex systems. For reasons of limited space, this section will not go into details about traditional methodologies, such as (Rational/Agile) Unified Process based on the Unified Modeling Language (UML) or Systems engineering methodologies based on SysML.

We preferred to introduce briefly the standard ISO/IEC/IEEE 42010 which proposes a methodology for the description of architectures in the area of software and system engineering [27]. This standard promotes a methodology for the creation, analysis and development of systems based on the use of descriptions of architectures. To this end, the standard proposes a core ontology for architecture descriptions. Figure 4, presents this core ontology.

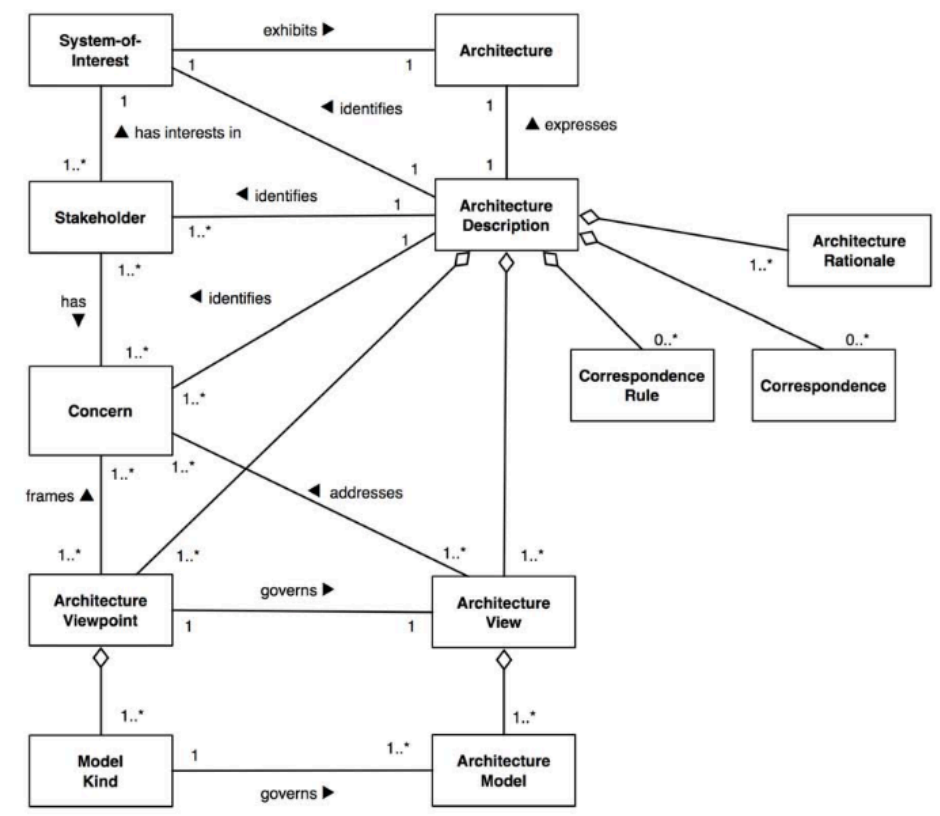

Fig. 3. Core ontology proposed by the standard ISO/IEC/IEEE 42010

One of the key elements of this core ontology are the architecture viewpoints and views, which are components of models capable of capturing the structural and behavioral foundations of a system architecture. 


\subsection{Semantic-driven Architecture}

Our architecture is based on the core ontology of the ISO/IEC/IEEE 42010 standard and proposes the definition of 5 viewpoints aimed at integrating the structural and behavioral architectural views of the Industry 4.0 CPS: connection, communication, coordination, cooperation and collaboration viewpoints (see Table 1).

Table 1. Viewpoints for a CPS layered reference architecture

\begin{tabular}{|c|c|c|c|}
\hline $\begin{array}{c}\text { Viewpoint } \\
\text { (Stakeholders) }\end{array}$ & Concern & & Description \\
\hline \multirow{3}{*}{$\begin{array}{l}\text { Connection } \\
\text { (IT Network } \\
\text { integrator) }\end{array}$} & \multirow{3}{*}{$\begin{array}{l}\text { IoE entities sharing } \\
\text { a common medium } \\
\text { or channel. }\end{array}$} & \multirow{3}{*}{$\begin{array}{l}\text { Network } \\
\text { Integrability }\end{array}$} & $\begin{array}{l}\text { End devices and access net- } \\
\text { works (Things and People) }\end{array}$ \\
\hline & & & Internet \\
\hline & & & $\begin{array}{l}\text { Data centers (Data, People and } \\
\text { Services) }\end{array}$ \\
\hline \multirow{11}{*}{$\begin{array}{l}\text { Communica- } \\
\text { tion } \\
\text { (IT Services } \\
\text { integrator) }\end{array}$} & \multirow{11}{*}{$\begin{array}{l}\text { IoE entities able to } \\
\text { understand each } \\
\text { other by exchang- } \\
\text { ing messages via a } \\
\text { common medium or } \\
\text { channel. }\end{array}$} & \multirow{3}{*}{$\begin{array}{l}\text { Middleware } \\
\text { Integrability }\end{array}$} & $\begin{array}{l}\text { Object/Procedure oriented } \\
\text { (ORB / RPC) }\end{array}$ \\
\hline & & & $\begin{array}{l}\text { Message/Event } \\
\text { (MOM / EDA) }\end{array}$ \\
\hline & & & $\begin{array}{l}\text { Service/Micro-service } \\
\text { ented (SOA / MSA) }\end{array}$ \\
\hline & & \multirow{3}{*}{ Interoperability } & Syntactic \\
\hline & & & Semantic \\
\hline & & & $\begin{array}{l}\text { Cross-domains and Open } \\
\text { standards }\end{array}$ \\
\hline & & \multirow{5}{*}{$\begin{array}{l}\text { Communication } \\
\text { modes }\end{array}$} & Synchronous/Asynchronous \\
\hline & & & $\begin{array}{l}\text { IN-only, IN-OUT, OUT-IN, } \\
\text { OUT-only }\end{array}$ \\
\hline & & & Request/Reply \\
\hline & & & Publish/Subscribe \\
\hline & & & Push/Pull \\
\hline $\begin{array}{l}\text { Coordination } \\
\text { (Business } \\
\text { process } \\
\text { designer) }\end{array}$ & $\begin{array}{l}\text { IoE entities work } \\
\text { together following } \\
\text { the orders or the in- } \\
\text { structions of a coor- } \\
\text { dinator. }\end{array}$ & $\begin{array}{l}\text { Intra-system } \\
\text { orchestration } \\
(\mathrm{CPS})\end{array}$ & $\begin{array}{l}\text { Service } \\
\text { orchestration within a business } \\
\text { domain }\end{array}$ \\
\hline $\begin{array}{l}\text { Cooperation } \\
\text { (CPS } \\
\text { Orchestrator) } \\
\end{array}$ & $\begin{array}{l}\text { CPS entities work } \\
\text { together to achieve } \\
\text { individual goals }\end{array}$ & $\begin{array}{l}\text { Inter-systems } \\
\text { choreography } \\
\text { (CPSoS) }\end{array}$ & $\begin{array}{l}\text { Service } \\
\text { choreography among several } \\
\text { business domains }\end{array}$ \\
\hline $\begin{array}{l}\text { Collaboration } \\
\text { (CPS } \\
\text { Choreogra- } \\
\text { pher) }\end{array}$ & $\begin{array}{l}\text { CPS entities work } \\
\text { together to achieve } \\
\text { a common global } \\
\text { goal }\end{array}$ & $\begin{array}{l}\text { Inter-systems or- } \\
\text { chestration } \\
\text { (CPSoS) }\end{array}$ & $\begin{array}{l}\text { Service } \\
\text { orchestration among several } \\
\text { business domains }\end{array}$ \\
\hline
\end{tabular}


Based on the Semantic-Driven Architecture (SDA) recommendation proposed by the OMG and in particular the Distributed Ontology, Modeling, and Specification Language (DOL) [29], the ontology providing the semantic basis for the architecture of CPS is presented in the figure 4. At the connection layer, the fully connected world (IoE) represented by the IoD, IoT, IoS and IoP actors are integrated in order to be part of a CPS. At the communication layer, the required interoperability services are provided in order guarantee the uniform access to the IoE actors (i.e. interoperable actors). At the coordination layers, the required operation processes (based on BPMN, CMMN and DMN specifications) can be designed and implemented in order to obtain concrete instances of CPSs, able to provide the expected product and services. At the cooperation layer, two or more CPSs (CPSoS) would be able to share resources or services, in order to achieve individual goals. Finally, at the collaboration layer, two or more cooperative CPSs (CPSoS) would be able to work together in order to achieve common goals.

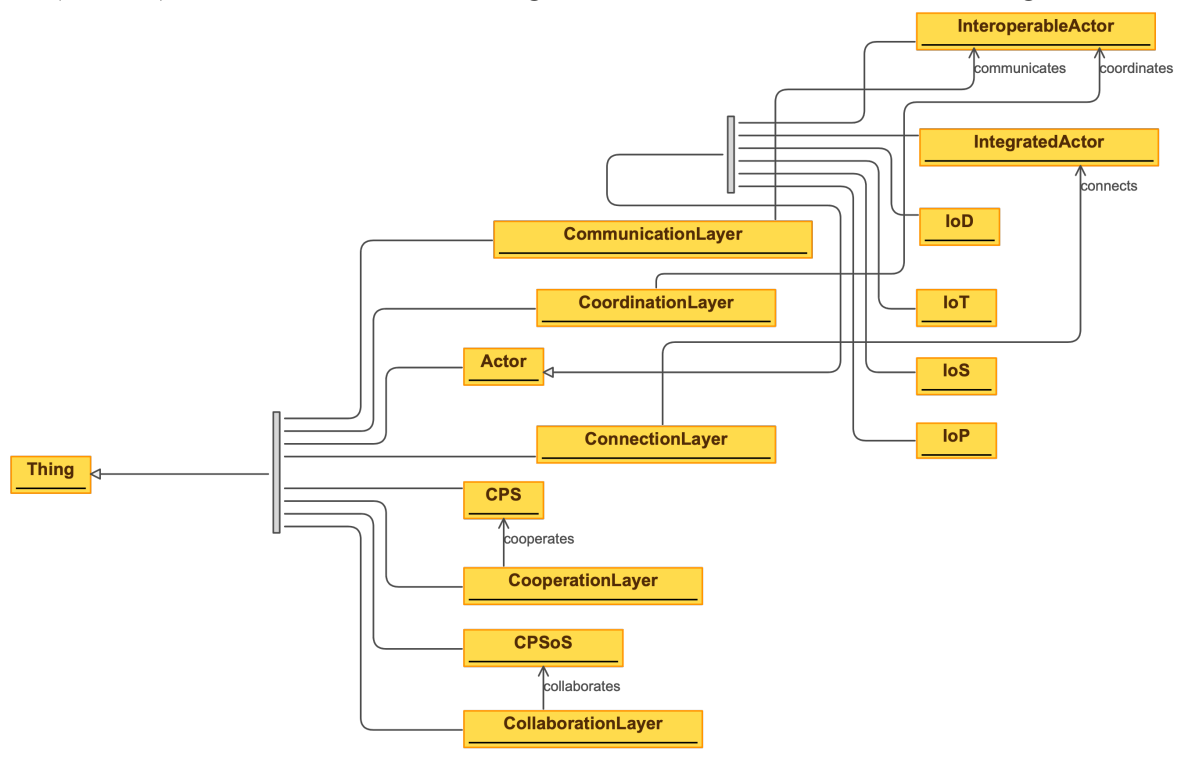

Fig. 4. Structural ontology of the CPS viewpoints.

Based on the semantic structure previously presented, the integration, interoperability and coordination of the CPSs can be guaranteed for operational processes of production and services. Additionally, the intelligent management of these processes, as well as the self-management capabilities that are required to implement smart CPS can be provided through the Autonomic Computing framework proposed by IBM [30]. An autonomic CPS (A-CPS) must implement autonomic processes for self-* functions based on monitoring, analyzing, planning and executing (MAPE) activities sharing a common knowledge base.

- Monitoring: retrieves state information of the IoE actors via the sensor interface. Relevant information is filtered and stored in the knowledge base. 
- Analyzing: compares the observed data from the expected values (symptoms) in order to detect an undesirable state (diagnosis)

- Planning: selects or elaborates strategies aimed at preventing or correcting an undesirable state or intended to achieve the targeted goals (treatment)

- Executing: executes the tuning actions on the IoE via the effector interface and traces this information in the knowledge base for future analysis and planning (treatment results)

The knowledge base is required in order to implement autonomic process based on observed values, the identification of symptoms and diagnosis and the execution of remedial treatments. The results observed from the treatment need to be captured in order to reconfigure the behavior if required. The behavioral ontology presented in figure 5, illustrates the basic entities and relationships enabling the implementation of autonomic process in order to add the self-management capabilities to the CPS.

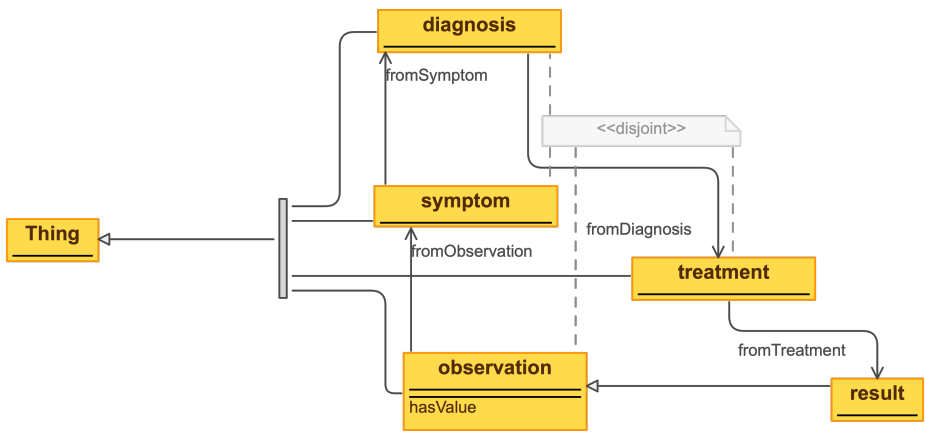

Fig. 5. Behavioral ontology of autonomic CPS (A-CPS).

\section{$5 \quad$ Conclusions and perspectives}

This research work has proposed a well-adapted methodology and a generic architectural framework aimed at facilitating the design and implementation of Autonomic Cyber Physical Systems (A-CPS) for the Industry 4.0. This architecture followed a multi-viewpoints approach and introduced the foundations of the structural and behavioral semantics of the integration, interoperation, coordination, cooperation and collaboration layers of A-CPS. The proposed semantic model is intended to design and implement the autonomic properties by incrementally including the required monitoring, analysis (diagnosis), planning and execution functions A-CPS. The proposed methodology and architectural framework will be integrated within the Capella MBSE opensource tool based on the ARCADIA methodology. 


\section{References}

1. X. Li, D. Li, J. Wan, A. V. Vasilakos, C.-F. Lai, and S. Wang, "A review of industrial wireless networks in the context of Industry 4.0," Wirel. Netw., vol. 23, no. 1, pp. 23-41, Jan. 2017.

2. A. Huber and A. Weiss, "Developing Human-Robot Interaction for an Industry 4.0 Robot: How Industry Workers Helped to Improve Remote-HRI to Physical-HRI," in Proceedings of the Companion of the 2017 ACM/IEEE International Conference on Human-Robot Interaction, New York, NY, USA, 2017, pp. 137-138.

3. $\mathrm{Xu}, \mathrm{Li} \mathrm{Da}$, Eric L. $\mathrm{Xu}$, and Ling Li. "Industry 4.0: state of the art and future trends." International Journal of Production Research 56.8 (2018): 2941-2962.

4. Liao, Yongxin, et al. "Past, present and future of Industry 4.0-a systematic literature review and research agenda proposal." International journal of production research 55.12 (2017): 3609-3629.

5. Zhong, R. Y., Xu, X., Klotz, E., \& Newman, S. T. Intelligent manufacturing in the context of industry 4.0: a review. Engineering, (2017), 3 (5), 616-630.

6. Ashton, Kevin. "That 'internet of things' thing." RFID journal 22.7 (2009): 97-114.

7. Gershenfeld, Neil, Raffi Krikorian, and Danny Cohen. "The internet of things." Scientific American 291.4 (2004): 76-81.

8. Atzori, Luigi, Antonio Iera, and Giacomo Morabito. "The internet of things: A survey." Computer networks 54.15 (2010): 2787-2805.

9. Wu, Geng, et al. "M2M: From mobile to embedded internet." IEEE Communications Magazine 49.4 (2011): 36-43.

10. Guinard, Dominique, and Vlad Trifa. "Towards the web of things: Web mashups for embedded devices." Workshop on Mashups, Enterprise Mashups and Lightweight Composition on the Web (MEM 2009), in proceedings of WWW (International World Wide Web Conferences), Madrid, Spain. Vol. 15. 2009.

11. Bradley, Joseph, Joel Barbier, and Doug Handler. "Embracing the Internet of everything to capture your share of $\$ 14.4$ trillion." White Paper, Cisco (2013).

12. Weber, Rolf H. "Internet of Things-New security and privacy challenges." Computer law \& security review 26.1 (2010): 23-30.

13. Schroth, Christoph, and Till Janner. "Web 2.0 and SOA: Converging concepts enabling the internet of services." IT professional 9.3 (2007): 36-41.

14. Conti, Marco, Andrea Passarella, and Sajal K. Das. "The Internet of People (IoP): A new wave in pervasive mobile computing." Pervasive and Mobile Computing 41 (2017): 1-27

15. Bordeleau, Fanny-Eve, Elaine Mosconi, and Luis Antonio Santa-Eulalia. "Business Intelligence in Industry 4.0: State of the art and research opportunities." Proceedings of the 51st Hawaii International Conference on System Sciences. 2018.

16. Lee, Jay, Hung-An Kao, and Shanhu Yang. "Service innovation and smart analytics for industry 4.0 and big data environment." Procedia Cirp 16 (2014): 3-8.

17. Wang, Shiyong, et al. "Towards smart factory for industry 4.0: a self-organized multi-agent system with big data based feedback and coordination." Computer Networks 101 (2016): 158-168.

18. Rajkumar, Ragunathan, et al. "Cyber-physical systems: the next computing revolution." Design Automation Conference. IEEE, 2010.

19. Tan, Ying, Steve Goddard, and Lance C. Pérez. "A prototype architecture for cyber-physical systems.” ACM Sigbed Review 5.1 (2008): 26. 
20. Lee, Edward A. "Cyber physical systems: Design challenges." 2008 11th IEEE International Symposium on Object and Component-Oriented Real-Time Distributed Computing (ISORC). IEEE, 2008.

21. Wang, Yübo, Thilo Towara, and Reiner Anderl. "Topological Approach for mapping technologies in reference architectural model Industrie 4.0 (RAMI 4.0)." Proceedings of the World Congress on Engineering and Computer Science. Vol. 2. 2017.

22. Zhong, R. Y., Xu, X., Klotz, E., \& Newman, S. T. (2017). Intelligent manufacturing in the context of industry 4.0: a review. Engineering, 3(5), 616-630.

23. Kagermann, H., Helbig, J., Hellinger, A., \& Wahlster, W. (2013). Recommendations for implementing the strategic initiative INDUSTRIE 4.0: Securing the future of German manufacturing industry; final report of the Industrie 4.0 Working Group. Forschungsunion.

24. Lin, S. W., Miller, B., Durand, J., Bleakley, G., Chigani, A., Martin, R., ... \& Crawford, M. (2017). The industrial internet of things volume G1: reference architecture. Industrial Internet Consortium, 10-46.

25. Li, Ling. "China's manufacturing locus in 2025: With a comparison of "Made-in-China 2025" and "Industry 4.0"." Technological Forecasting and Social Change 135 (2018): 6674.

26. Zhong, R. Y., Xu, X., Klotz, E., \& Newman, S. T. (2017). Intelligent manufacturing in the context of industry 4.0: a review. Engineering, 3(5), 616-630.

27. ISO. ISO/IEC 42010 Systems and Software Engineering - Architectural Description, 2011.

28. Roques, Pascal. "MBSE with the ARCADIA Method and the Capella Tool." 2016.

29. Object Management Groupe. Distributed Ontology, Modeling, and Specification Language (DOL), 2018

30. Kephart, Jeffrey O., and David M. Chess. "The vision of autonomic computing." Computer 1 (2003): 41-50. 